\title{
A VIOLÊNCIA ENQUANTO FENÔMENO SOCIAL: AS MORTES REAIS E SIMBÓLICAS DO JOVEM DA PERIFERIA
}

\author{
Ruth Tainá Aparecida Piveta ${ }^{1}$
}

\section{Introdução}

Esse artigo visa problematizar um fenômeno que tem atravessado o cenário brasileiro de forma bastante expressiva nas últimas décadas: a violência letal cometida contra uma parcela da juventude do país, em específico, jovens pobres, negros e moradores de territórios considerados periféricos. Essa violência, fruto de relações históricas, tem sido, por uma série de estratégias e práticas, silenciada, legitimada e subnotificada. Por ela, as vidas perdidas tornam-se apenas números e porcentagens em dados estatísticos, geralmente noticiados por mídias locais.

O desejo por problematizar teoricamente essa questão parte de uma série de experiências advindas do cotidiano de trabalho como psicóloga na Política de Assistência Social. Nesse contexto de trabalho, são recorrentes os relatos sobre adolescentes e jovens assassinados - em seus territórios, em supostos confrontos com a polícia, em conflitos com outros jovens. Mortes que parecem ser naturalizadas e que pouco ou nada causam de comoção social; mortes que não têm visibilidade. Esses jovens que morrem carregam um estigma, uma marca de diferenciação, que os assinala como uma parcela da sociedade sob a qual a regra válida é a "lei da bala” e para os quais, muitas vezes, existem somente dois destinos de vida possíveis: “o cemitério ou a cadeia”, como os próprios jovens costumam dizer.

A proposta desse artigo, portanto, é trazer para discussão alguns elementos relacionados à violência letal que vem se configurando como uma das principais causas de morte de jovens no Brasil. Como veremos, tal prática de violência tem sido endereçada, principalmente, à juventude pobre, negra e habitante de territórios

1 Universidade Norte do Paraná, Brasil.

Iluminuras, Porto Alegre, v. 19, n. 47, p. 162-184, dec, 2018. 
considerados periféricos em relação aos centros urbanos. Iniciaremos apresentando alguns dados estatísticos oficiais acerca das práticas de violência que incidem sobre a população jovem brasileira. Posteriormente, trabalharemos conceitualmente a questão da violência, bem como algumas estratégias discursivas que, historicamente, acabam por legitimar práticas violentas e estigmatização de certas populações no cenário brasileiro.

Para abordar a questão, principalmente no que diz respeito à violência letal e às práticas de extermínio e genocídio que a circundam, trabalharemos com dados obtidos dos Mapas da Violência (Waiselfisz, 2014, 2015, 2016), com os Atlas da Violência 2016 e 2017 (Cerqueira et al., 2016, 2017) e o Índice de Homicídios na Adolescência (IHA, 2014), aliando a leitura desses dados a elementos conceituais que poderão ajudar a problematizar a arquitetura dessas práticas violentas. Os Mapas da Violência começaram a ser elaborados em 1998 com o objetivo de subsidiar uma série de pesquisas que eram desenvolvidas pela Organização das Nações Unidas para Educação, Ciência e Cultura - UNESCO - no país a partir das temáticas da juventude e violência. Posteriormente, começaram a ser utilizados como subsídios para a construção de políticas públicas afeitas à área da juventude e aplicados por instituições, inclusive governamentais, sendo, atualmente, publicados em parceria com o Governo Federal (Waiselfisz, 2014). Dada sua ampla utilização, os consideramos de extrema relevância para este trabalho. O Atlas da Violência, por sua vez, é produzido pelo Instituto de Pesquisa Econômica Aplicada (IPEA) em parceria com o Fórum Brasileiro de Segurança Pública, com o objetivo de auxiliar pesquisas sobre as temáticas da criminalidade e violência, contando atualmente com duas edições - 2016 e 2017.

\section{A violência em números: quando a juventude é o alvo}

Os documentos em análise trazem, como preocupação central, a quantidade de mortes de jovens que vem ocorrendo no Brasil nessas últimas três décadas e apontam que há um processo em curso, desde a década de 1980, que vitima cada vez mais cedo a população jovem. Apontam que "enquanto no começo da década de oitenta, o pico da 


\section{A Violência enquanto Fenômeno Social..}

taxa de homicídio se dava aos 25 anos, atualmente esse gira na ordem de 21 anos” (Cerqueira et al., 2017: 25).

Neste contexto, os homicídios representam, atualmente, a principal causa da mortalidade juvenil quando comparados a outros dois elementos que compõem a categorização de “causas externas” da morte, segundo o CID-10: o suicídio e os acidentes de trânsito. Com base nos dados, pode-se afirmar que a juventude é a principal vítima da violência homicida no Brasil, como podemos observar a partir da análise feita no Mapa da Violência 2014: Os Jovens do Brasil, quando se afirma que: "na população não jovem só $2,0 \%$ dos óbitos foram causados por homicídio, entre os jovens os homicídios foram responsáveis por 28,8\% das mortes acontecidas no período 1980 a 2012” (Waiselfisz, 2014: 25).

O Índice de Homicídios na Adolescência aponta "um aumento das taxas de homicídio, tanto entre jovens negros como entre jovens brancos, em praticamente todas as regiões” (IHA, 2014: 28). Também, o Atlas da Violência confirma essa assertiva, “46,4\% dos óbitos de homens na faixa etária de quinze a vinte e nove anos são ocasionados por homicídios. Se considerarmos apenas os homens com idade entre 15 a 19 anos, esse indicador tem a incrível marca dos 53\%” (Cerqueira et al., 2016: 6).

Esses elementos iniciais cooperam para realizar um contraponto em relação aos discursos hegemônicos circulantes em relação à juventude das periferias, que a avaliam como perigosa e violenta. A partir dessa leitura de ordem quantitativa, podemos dizer que os adolescentes e jovens no Brasil têm sido alvo de práticas violentas de forma incisiva, como apontam os dados do Atlas da Violência 2017, evidenciando que no Brasil “mais de 318 mil jovens foram assassinados entre 2005 e 2015” (Cerqueira et al., 2017: 25).

Quando se analisa a maneira como ocorrem essas mortes, temos como protagonista os homicídios por arma de fogo (AF), representando cerca de 33\% dos óbitos juvenis (Waiselfisz, 2015) “com pico nos 20 anos de idade, quando os homicídios por AF atingem a impressionante marca de 67,4 mortes por 100 mil jovens” (Waiselfisz, 2016: 51), sendo que “em conjunto, a partir dos 19 anos de idade, e até os 26, as taxas de mortalidade violenta ultrapassam os 100 óbitos por 100 mil jovens” 
(Waiselfisz, 2014: 24). Considerando o intervalo de 1980 a 2012, há um indicativo quantitativo de que 56,5\% das vítimas por disparo de armas de fogo foram jovens na faixa de 15 a 29 anos (Waiselfisz, 2015). O gráfico abaixo apresenta as taxas de homicídios por AF no Brasil a cada 100 mil habitantes e por idade. Ele auxilia na visualização dos dados apresentados:

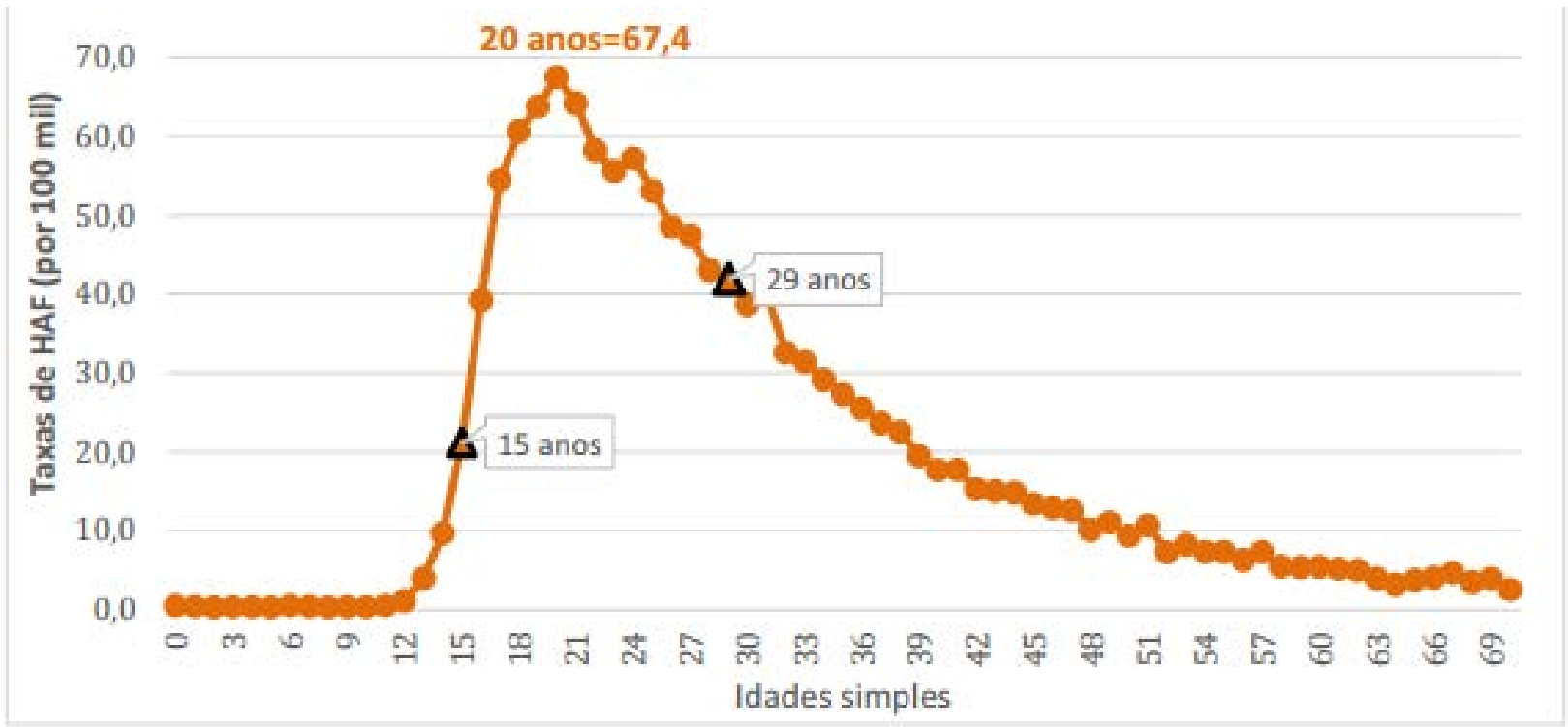

Gráfico 1 - Taxas de homicídios por AF no Brasil a cada 100 mil habitantes por idade (2014) Fonte: Adaptado de Waiselfisz (2016: 51).

É importante salientar que, no que diz respeito à população geral, os indicadores apontam uma queda nos índices de mortalidade "de 631 por 100 mil habitantes, em 1980, para 608, em 2012” (Waiselfisz, 2014: 23), demonstrando uma evidente melhoria na expectativa de vida da população, inclusive incidindo em avanços do Índice de Desenvolvimento Humano (IDH) no país. No entanto, quando olhamos para a juventude, os indicadores apontam outra situação, na qual “apesar dos ganhos globais, a taxa de mortalidade juvenil manteve-se estagnada, e até teve um ínfimo aumento ao longo do período, passando de 146 mortes por 100 mil jovens, em 1980, para 149, em 2012” (Waiselfisz, 2014: 23).

Dentro desse universo, e na tentativa de traçar um perfil das vítimas, dois aspectos são evidenciados pelas estatísticas: a questão racial e a de gênero. Somados, 


\section{A Violência enquanto Fenômeno Social..}

esses indicadores nos fornecem um retrato bastante específico sobre qual recorte da população jovem é, de fato, vítima da violência letal em nosso país: homens jovens negros, na faixa etária dos 16 aos 22 anos (Waiselfisz, 2016). No que diz respeito à questão da morte de homens jovens nesse recorte, os dados apresentados pelo Atlas da Violência de 2017 apontam que:

Somado a isso, no que diz respeito às mortes por AF, tem-se o indicativo de que 95\% desses óbitos correspondem a homens (Waiselfisz, 2016). Aponta-se, portanto, uma “elevada proporção de mortes masculinas nos diversos capítulos da violência letal do país, principalmente quando a causa são os homicídios” (Waiselfisz, 2014: 70).

Outro dado importante a ser considerado, nessa análise, refere-se à questão racial. Os dados indicam que "de cada 100 pessoas que sofrem homicídio no Brasil, 71 são negras” (Cerqueira et al., 2017: 30), sendo que “a vitimização negra entre os jovens passa de 85\% em 2002 para 175\% em 2012: aumenta 105,5\%” (Waiselfisz, 2014: 163). Entre os vinte e vinte e um anos de idade, a chance de um jovem negro ser assassinado é 147\% maior em relação a outros segmentos (Cerqueira, 2016). Observa-se, ainda, uma tendência de diminuição no número de homicídios da população branca e aumento na população negra, tanto na população geral quanto na população jovem, sendo que

[...] entre os brancos, no conjunto da população, o número de vítimas diminui de 19.846 em 2002 para 14.928 em 2012, o que representa uma queda de 24,8\%. Entre os negros, as vítimas aumentam de 29.656 para 41.127 nessas mesmas datas: crescimento de 38,7\% (Waiselfisz, 2014: 150).

O gráfico a seguir permite visualizar essa afirmativa, ao indicar a probabilidade de ser vítima de homicídio quando se é um homem negro ou branco: 


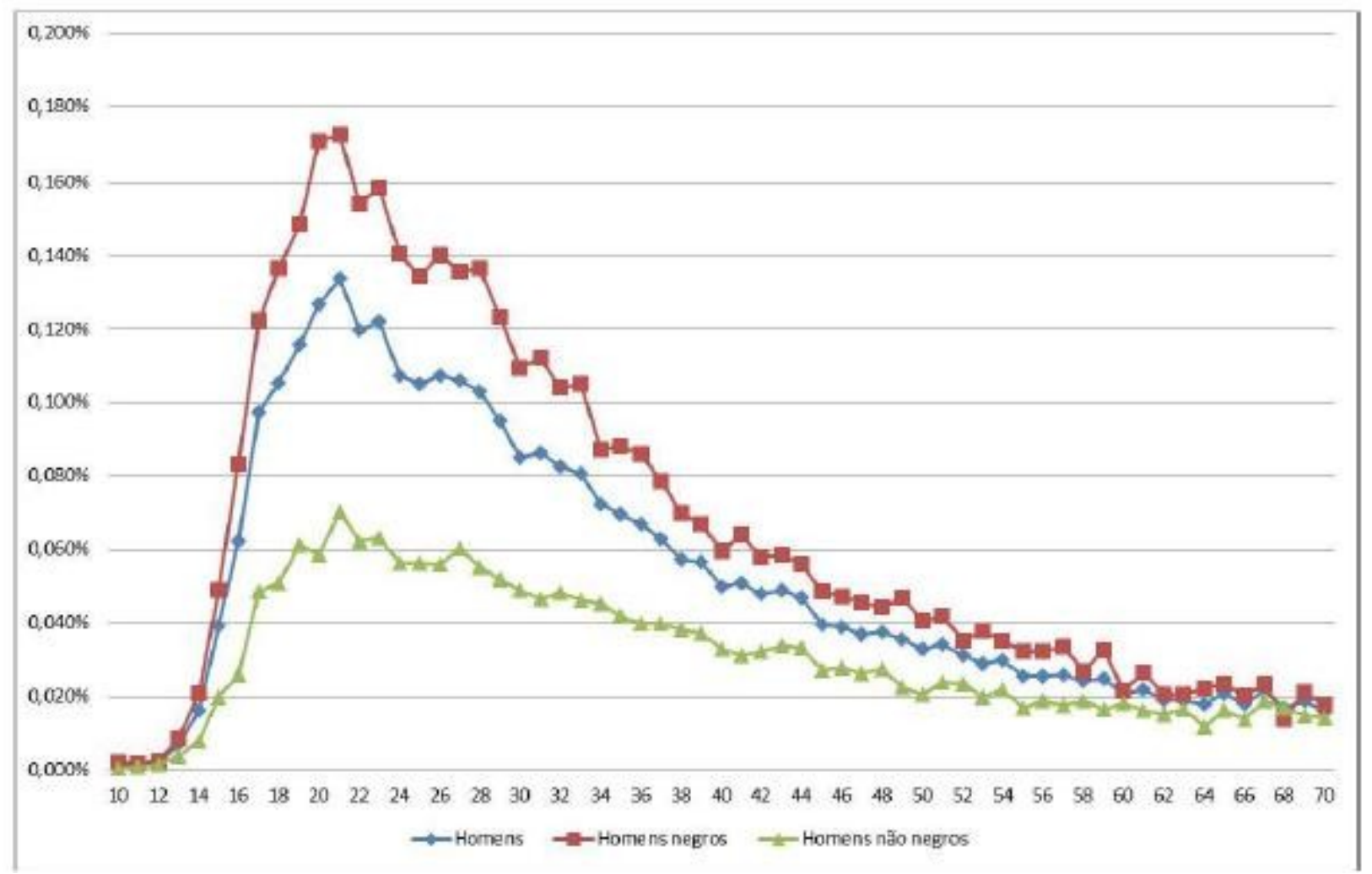

Gráfico 2 - Probabilidade de ser vítima de homicídio por idade, segundo a raça/cor Fonte: Cerqueira et al. (2016: 22).

Em relação a essa seletividade, há que se considerar, ainda, a questão do acesso à renda vinculado a aspectos raciais, que nos auxilia na composição da imagem dos jovens que são mortos no Brasil. Segundo dados do IBGE de pesquisa domiciliar realizada em 2011, famílias brancas tendem a receber uma renda média 75,2\% maior que famílias negras (Waiselfisz, 2015). Dadas as condições históricas marcadas pela escravização da população negra, que é marca significativa na formação da sociedade brasileira, o racismo, velado ou não, é elemento que acaba por permear as relações sociais, econômicas e políticas voltadas às pessoas negras. Entre outros aspectos, isso reflete, inclusive, no que diz respeito ao acesso à renda da população negra, que participa desigualmente das condições de sobrevivência no sistema capitalista, ocupando as margens sociais também por conta da situação de pobreza muitas vezes vivenciada. O racismo, nesse sentido, assume contornos múltiplos,

Iluminuras, Porto Alegre, v. 19, n. 47, p. 162-184, dec, 2018. 


\section{A Violência enquanto Fenômeno Social..}

é institucionalizado e se materializa em práticas variadas, nos mais diferentes equipamentos e organizações, em saberes e, até mesmo, em opressões e dominações que fazem parte do que Foucault (1995) denominou de governamentalidades, baseadas em processos de dominação social, cultural e econômica. No caso da dominação racial, voltada diretamente contra os negros, é possível delimitar o quanto a margem de liberdade e acessos está restrita nas denominadas democracias atuais (Lemos et al., 2017: 169).

Assim, se são homens jovens e negros os principais alvos dos homicídios no país, há que se somar a essa composição a questão da pobreza. Conforme já discutido no primeiro capítulo, é ao jovem pobre que, historicamente, se vincula a questão da delinquência, do risco e do perigo e é sobre seu corpo que incide a violência, perpetrada pela sociedade e pelo Estado.

Ainda em relação à questão da pobreza, vale ressaltar que o acesso à renda está, na sociedade capitalista, intimamente relacionado ao acesso a bens e serviços, inclusive aqueles que deveriam ser ofertados com qualidade pelos governos. Com a progressiva privatização de serviços básicos e o sucateamento dos serviços públicos, o acesso à educação, saúde, lazer, moradia, segurança pública e outras dimensões da vida cidadã - que, legalmente, se constituem como direitos constitucionais universais que deveriam alcançar toda a população brasileira - fica prejudicado, principalmente nos espaços de moradia das camadas populares. A respeito da segurança pública, por exemplo, Waiselfisz afirma:

Em teoria, setores e áreas mais abastadas, geralmente brancas, têm uma dupla segurança: a pública e a privada, enquanto os menos abastados, que vivem nas periferias, preferencialmente negros, têm que se contentar com o mínimo de segurança que o Estado oferece (Waiselfisz, 2015: 102).

A segurança que o Estado oferece aparece para essas populações, muitas vezes, com contornos de extrema violência, tendo em vista a "lógica militar” (Silva, 2014: 30) ligada ao caráter repressivo assumido nesse contexto e vinculada à guerra às drogas e à criminalidade. Há, portanto, uma variação das modalidades de presença das instituições estatais nas camadas populares (Silva, 2014): um Estado de Direito reduzido em sua função protetiva e um Estado Penal intensificado em sua função repressiva.

A respeito desse contexto de repressão, Feltran (Feltran, 2011) afirma que o olhar dos operadores da segurança acaba por se vincular ao indivíduo e não necessariamente ao ato ilícito cometido. Isso se desdobra em uma lógica que pune e 
vigia qualquer corpo que se assemelhe à imagem daquele que corporifica a delinquência. Na experiência laboral de trabalho em equipamentos da Política de Assistência Social, - que atende, em sua maioria, pessoas que experienciam a pobreza e o não acesso a direitos e serviços públicos - são comuns, no cotidiano de escuta de jovens das periferias, as narrativas de abordagens policiais violentas, tanto em seus territórios quanto nos momentos em que frequentam outros espaços da cidade, resultando muitas vezes em agressões e humilhações públicas. Muito comum, também, é ouvir das famílias os abusos materializados nas invasões de domicílio pela polícia, por vezes, sem mandato oficial e com extrema truculência, ofensas gratuitas, hostilidades e agressões. Nessa lógica de segurança que se configura,

O verbo empregado é o ser. Se é bandido, o sujeito passa a conter o ato ilegal em sua natureza: seu corpo passa a demonstrar o indivíduo ilegal, é ele quem passa a ser um fora da lei. [...] Absoluto no corpo do praticante, o ato ilícito passa também a comandar o olhar das forças da ordem para os corpos daqueles que lhe são semelhantes. Irmão, amigos, parentes, aqueles que tem a mesma cor, vestem-se da mesma forma (Feltran, 2011: 132).

A segurança perpetrada principalmente pela polícia militar para essa parcela da população é, contraditoriamente, extremamente violenta - abusos policiais, agressões e mortes são causadas por esses agentes de proteção social, cotidianamente. A esse respeito, o Atlas da violência 2017 afirma que a letalidade policial é produto de "um modelo de enfrentamento à violência e criminalidade que permanece insulado em sua concepção belicista, que pouco dialoga com a sociedade ou com outros setores da administração pública” (Cerqueira et al., 2017: 22), pautada em um formato de segurança pública que "se não promove, é conivente com o uso abusivo da força letal e execuções sumárias, ao mesmo tempo que expõe e vitimiza cada vez mais os seus agentes” (Cerqueira et al., 2017: 21). Em relação à distribuição geográfica desses assassinatos, Waiselfisz (Waiselfísz, 2016) afirma que há uma mudança em curso na última década. Se, anteriormente, a incidência das mortes de jovens era intensa nas grandes capitais, como Rio de Janeiro e São Paulo, o que se observa, nos últimos anos, é a disseminação dessas práticas nas cidades do interior dos estados, bem como nas cidades que compõem a região nordeste do país. Desse modo, o número de mortes 


\section{A Violência enquanto Fenômeno Social..}

tem atingido "crescentemente os moradores de cidades menores no interior do país e no Nordeste, sendo as principais vítimas jovens e negros” (Cerqueira, 2016: 5).

Tal fenômeno pode ser explicado pela expansão do desenvolvimento econômico a partir da década de 1990 no país, originando, no interior dos estados, novos polos de oferta de emprego, investimentos e migrações, modificando as configurações desses espaços. Esse fato, somado às insuficiências das políticas sociais e à lógica punitiva da segurança pública frente às classes mais empobrecidas, acabam por contribuir para o desenvolvimento e fortalecimento também da criminalidade e da violência nessas regiões.

Apresentados os dados estatísticos, vale considerar que esses são um recorte, que representa uma parcela das violências e violações sofridas pelos jovens em nosso país. Trata-se da "ponta do iceberg, uma mínima parcela das agressões, negligências e violências que, de fato, existem e subsistem em nossa sociedade” (Waiselfisz, 2015: 5), haja vista a grande dificuldade de promover notificações adequadas e fidedignas das ocorrências, bem como as subnotificações. Não obstante, a juventude que vem sendo vítima da violência letal vai tomando formas bastante delineadas: o jovem negro e pobre. Sobre suas vidas incide a produção de uma série de efeitos: atos de violência, preconceito e estigmatização, perpetradas entre os próprios pares, a sociedade e o Estado.

\section{A violência enquanto fenômeno social: atravessamentos subjetivos}

A conjuntura apresentada nos questiona sobre os motivos dessas mortes, bem como sobre o silêncio social diante dessas estatísticas. Que elementos operam socialmente, banalizando, legitimando e invisibilizando as mortes de jovens negros e pobres em nosso país, marcando-os como vidas que não merecem viver? Quais os elementos que tornam, na sociedade contemporânea, algumas vidas mais valorizadas que outras?

O desafio, nesse contexto, é problematizar as dimensões subjetivas que estão em jogo neste campo de tensões entre as imagens produzidas socialmente em relação a 
esses jovens, que circulam e nos atravessam cotidianamente, e suas construções como sujeitos, corpos marcados insistentemente pela marginalização e pelo preconceito. Seus corpos, socialmente, circulam como imagens do risco, são a corporificação do crime e da violência e, assim sendo, necessitam ser barrados, punidos e, tal como demonstrado nas estatísticas, exterminados.

A vida desses jovens, desde a perspectiva aqui adotada, se produz como uma teia - de significados, sentimentos, pertencimentos e exclusões - que marca seus corpos e compõe seus processos subjetivos. Nesse caso, para apreender o que é ser 'jovem de periferia', ou como se articulam as 'juventudes’ nesse contexto, faz-se necessário entender a partir de quais elementos discursivos, geográficos, históricos, políticos e econômicos vai se construindo essa vida.

Trata-se, aqui, da concepção da subjetividade como multiplicidade, sendo “essencialmente fabricada, modelada, recebida, consumida” (Guattari; Rolnik, 2000: 25) no registro do social. Vida polifônica, construída a partir de muitas vozes. Forjada nas relações, nos encontros e nos afetos, em meio a múltiplos agenciamentos que atravessam o campo social e, invariavelmente, nossos corpos. Nesse caso, não existem sujeitos prontos, dados de antemão. Cada sujeito é uma construção, um processo. Construção essa que se materializa no corpo, "superfície de inscrição dos acontecimentos” (Foucault, 1979: 22) - marcado e constituído pela história e que “atesta a ação das forças sociais que circula, em um dado tempo histórico” (Tarres; Martínez; Mansano, 2016: 220).

Portanto, cabe pensar como se constitui esse sujeito - o jovem da periferia nas entrelinhas dos regimes de verdade em curso nesse período histórico, tendo em vista que "é nessa inscrição histórica e cultural das práticas concretas que o sujeito é constituído na imanência de um campo de conhecimento” (Takeiti, 2011: 68-69). Compreendemos, portanto, a juventude como pluralidade, vivida e sentida de formas distintas a depender de uma série de experiências a que são expostos os jovens em seus diferentes contextos de vida. Esses necessitam ser considerados, correndo-se o risco, caso contrário, de cair na armadilha da generalização a partir de categorias universalizantes. Desse modo, 
[...] é preciso considerar que a constituição da condição de jovem ocorre em meio a conjunturas variadas e não como um processo único. Considerando sua interpretação mediante os processos e relações de poder social, político e econômico, pode-se afirmar que o conceito e a configuração de juventude indica a existência de muitas juventudes. Portanto, não se pode afirmar que a juventude das camadas populares perpassa pelas mesmas condições que a juventude das elites ou vice-versa (Bernardo, 2008: 2).

Trata-se, aqui, de um recorte específico - a juventude pobre - compreendido como um conjunto de modos de vida característicos, diferentes de outras formas de vivenciar esse momento da vida. Em relação a esse recorte, há que se ter cuidado com a naturalização, feita em geral, da vinculação de juventude-vulnerabilidade- violência, que muitas vezes acaba por situar a priori a violência nos jovens das classes populares, como se fosse a única forma de sociabilidade possível a eles (Takeiti, 2011). Nesse sentido, o próprio recorte adotado carrega em si multiplicidades que, ainda que não sejam tomadas em análise, evidencia a importância de situá-las. Assim como não há uma juventude universal, não há uma juventude pobre cristalizada em um formato único.

Talvez um elemento convergente a esses jovens seja a experiência de situações de violência em seu cotidiano. Violência essa que se materializa na dificuldade de acesso a serviços públicos, nos preconceitos vinculados aos locais de moradia, nas práticas repressivas do Estado fortemente presentes nas periferias, na convivência cotidiana com o tráfico de drogas, na inserção precoce no mundo do crime, no racismo, nas agressões físicas e simbólicas, nos homicídios.

Há um extermínio em cena, relacionado à população pobre e, consequentemente, à juventude pobre, que se manifesta de diversas formas: desde o acesso limitado a serviços de saúde e informações sobre direitos sociais, a vivência da fome e da miséria (sua ou de seus próximos), a falta de saneamento básico em alguns territórios, a violência policial, culminando com os homicídios. Sobre essas práticas de extermínio, há que se ressaltar, portanto, que os homicídios e as mortes violentas se configuram como o ponto extremo de uma série de práticas, que tem como efeito a morte ou o adoecimento das populações periféricas.

Quando analisadas historicamente, é possível perceber que as relações 
violentas têm sido uma marca constante na sociedade brasileira, sendo disseminadas, autorizadas e, em alguns momentos históricos do país, utilizadas como estratégia governamental. Tal fato "nos lega como patrimônio coletivo a banalização da vida, a naturalização da morte e a cultura da impunidade” (Almeida, 2004: 49). Assim, pensar a violência cometida contra a juventude brasileira é, de alguma forma, pensar as formas de sociabilidade por meio das quais nos constituímos como povo, desde aspectos culturais, valorativos, saberes e discursos que se constroem e se perpetuam no tecido social.

A violência, compreendida enquanto questão social, é conceito de difícil caracterização, tendo em vista que se trata de um fenômeno complexo e multifacetado, que se manifesta de inúmeras formas nas diversas configurações de sociedade. Nesse sentido, "não existe uma única percepção do que seja violência, mas multiplicidade de atos violentos, cujas significações devem ser analisadas a partir das normas, das condições e dos contextos sociais, variando de um período histórico a outro (Abramovay et al., 2002: 17).

Problematizá-la implica, portanto, problematizar as relações estabelecidas em um contexto histórico, com atenção às relações de poder em jogo que abarcam diversas expressões das diferenças sociais, desde a desigualdade de renda às "relações de gênero, de etnia e de cultura, eixos que, igualmente, compõem os processos sociais” (Lopes et al., 2008: 66). Em cada situação de violência, pode-se perceber a existência de "uma rede intrincada de fatores que envolvem aspectos micro e macrossociais, bem como perspectivas da subjetividade dos atores sociais envolvidos” (Rizzini; Limongi, 2016: 40).

Assim, a violência implica um modo de relação historicamente produzido, mas também um elemento constitutivo inerente à vida em sociedade, estando presente em todas as configurações sociais, desde o momento em que leis e normas foram criadas para regular a vida e as relações humanas. Reconhecer tal fato auxilia no exercício de análise das práticas violentas. A esse respeito, Carvalho afirma:

Primeiramente, cabe renunciar a uma condenação moral demasiadamente rápida e

Iluminuras, Porto Alegre, v. 19, n. 47, p. 162-184, dec, 2018. 


\section{A Violência enquanto Fenômeno Social..}

simplista das condições que a vida em sociedade hoje nos oferece. Não se trata de aceitar passivamente a violência presente no cotidiano, mas de reconhecer que até mesmo a moral, esta mesma utilizada para a condenação da violência, se constituiu ao longo da história pela violência continuada. Nossos valores, o nosso "bem" e o nosso "mal”, foram banhados em sangue humano, diz Nietzsche (Carvalho, 2012: $16)$.

No contexto brasileiro, a violência é uma constante, atravessando os diversos regimes políticos e econômicos como uma das principais variáveis na construção da sociedade, sendo nossa colonização fundada na morte e destruição de centenas de populações indígenas. Além disso, as heranças escravocratas fazem parte de nossa constituição enquanto sociedade, pautadas em diversas violências dirigidas aos escravizados, marcando nossa população, sendo o racismo e a discriminação racial efeitos duradouros e contemporâneos dessas relações (Rizzini, 2016; Pereira, 2010). No entanto, ainda que tais marcas sejam perenes, há que se levar em consideração que

embora historicamente a sociedade brasileira tenha sido construída com o recurso constante à violência, esta tem sido sistematicamente negada a nível ideológico. [...], no Brasil haveria uma índole pacífica supostamente herdada do português, que teria sabido tão gostosamente promover uma suave mistura de raças, criando aqui nos trópicos uma sociedade harmônica (Oliven , 2010: 6).

Distante da realidade de nosso país, essa “índole pacífica” ganha contornos de mito. Mito esse que passa a ser contestado na delimitação de imagens de indivíduos eleitos como ameaça à ordem e que, portanto, devem ser controlados e punidos. Interessa aqui pensar a ameaça que, por uma série de fatores, vai ser localizada nas classes populares e, mais especificamente, na juventude pobre (Oliven, 2010).

\section{Violência urbana: os modos de habitar a cidade}

Para aprofundar a discussão acerca da violência e seus efeitos, há que se falar aqui da chamada violência urbana, expressa nos espaços coletivos da vida social e que é, geralmente, associada ao cotidiano das grandes cidades (Rizzini, 2016). A cidade é vista como espaço de convivência de diversas condições de vida, incluídas também as relações violentas e criminosas, intimamente vinculadas às profundas desigualdades sociais vivenciadas cotidianamente como efeitos do capitalismo. Neste sentido, 
A experiência da cidade e da violência é uma experiência partilhada por todos, embora vivida sob condições de extremada diferença. Os contrastes aparecem no tecido urbano de modo muito explícito. Não há só o crescimento e a dispersão dos bairros populares da periferia, mas áreas do centro da cidade que se transformam em guetos urbanos onde vivem os mais pobres (Mello, 2002: 131).

Há, portanto, um elemento de segregação vinculado a esses contrastes que perpassa a experiência da violência urbana, sendo os espaços das periferias e bairros populares avaliados por uma parcela da sociedade como lugares perigosos. A cidade é vivenciada de formas distintas, dada essa segregação, proporcionando experiências subjetivas também distintas. Esses aspectos, associados a interesses econômicos, acabam por agravar a violência e a criminalidade nos territórios periféricos, principalmente com a expansão do tráfico de drogas e armas que tem se fortalecido no Brasil desde a década de 1980. A esse respeito, Silva afirma:

A expansão da violência urbana parece estar umbilicalmente ligada à economia internacional da droga, em particular da cocaína, que se acrescentou à secular cadeia produtiva, muito mais modesta, da maconha. $\mathrm{O}$ tráfico em pontos fixos, ao mesmo tempo em que, sendo ilegal, não pode prescindir do recurso à violência privada, confere uma base estável que permite a reprodução continuada dessa forma de "capitalismo aventureiro", para usar a expressão de Max Weber. Por isso, muitas outras atividades criminais, violentas ou não, que raramente têm capacidade de se reproduzir sem interrupção, tendem, direta ou indiretamente, a gravitar em torno dele (Silva, 2010: 284).

O agravante nesse caso é que, tendo em vista a histórica segregação das favelas e periferias, houve um favorecimento da implantação dos comércios das drogas em seus territórios, inclusive com a consolidação e fortalecimento do crime organizado. Tais elementos acabam por fortalecer a imagem das periferias como locais de perigo e risco, sob as quais incidem práticas repressivas recorrentes, como as operações policiais, configurando-se em “ações pautadas por uma lógica punitiva que criminaliza a pobreza e policiza o social” (Rizzini, 2016: 35). Tais ações são vinculadas à política de guerra às drogas adotada no país a exemplo dos modelos estadunidenses. Essa política "passou a ser organizada pela prisão em massa e pela matança dos que foram forjados como monstros sociais, os classificados juridicamente como traficantes na lógica penal.” (Lemos et al., 2017: 169), incidindo principalmente sobre os territórios das periferias. Assim, aos moradores desses espaços, em sua maioria pessoas pobres, a experiência da 
cidade, muitas vezes, está vinculada à hostilidade e ao mínimo acesso aos direitos. Dessa forma, pode-se dizer que:

a cidade tem muros e divide quem pode transitar por ela e quem não pode, de maneira que, se ousar ultrapassar os limites, poderá ser eliminado como refugo social, sem a mínima culpa e inquietação por grande parte da população, a qual tem uma opinião estereotipada constituída pelas mídias oligárquicas e não democráticas (Lemos et al., 2017: 171).

A esse respeito, Silva (2010) apresenta elementos que contrapõem a ideia amplamente disseminada de que as periferias seriam os espaços do perigo e, consequentemente, habitadas por pessoas perigosas e de índole duvidosa. O autor discute que

o fato de que os "territórios da pobreza", de uma maneira geral, tendem a ser, mundo afora [...], mais intensamente afetados pela violência policial e criminal associada ao comércio de drogas, não indica nenhuma dependência causal das disposições morais ou da conduta do conjunto dos moradores. Primeiro, porque as linhas de comando da cadeia produtiva estão fora dessas áreas e do próprio território nacional. Segundo, porque é sabido que a localização física do varejo está muito longe de restringir-se a esses espaços urbanos mais desfavorecidos, que respondem apenas pela maior visibilidade desse tipo de atividade. Finalmente, porque tanto a estratégia locacional quanto o pessoal nela ocupado dependem do tipo de droga transacionada (Silva, 2010: 285).

No que tange ao recorte da juventude, que aqui nos interessa, vale afirmar que suas configurações são também fortemente atravessadas por esse elemento, sendo os jovens pobres e moradores das periferias os mais atingidos pela violência, pois, "para os jovens que diariamente convivem com situações de violência, essas passam a fazer parte de suas escolhas e decisões, do presente e do futuro e deixam marcas físicas e/ou psíquicas por toda a vida” (Rizzini, 2016: 38).

A essas experiências citadas, somam-se as experiências de preconceito e estigmatização, também cotidianas, bem como práticas de extermínio que, dadas as estatísticas apresentadas, consolidam-se como ação habitual para esse recorte populacional. Para essa juventude, o olhar do Estado parece incidir por meio de outras regras, sendo essas vidas lembradas apenas como estatísticas e, juridicamente, muitas vezes, não recebem uma investigação precisa. Essa regulação seletiva da vida que incide sobre a vida dos jovens pobres

é um efeito dos mecanismos de segurança e das práticas biopolíticas. O fazer viver e 
o deixar morrer alguns grupos sociais implica em defender determinados segmentos da população, no interior do Estado Democrático de Direito. O extermínio de pessoas, avaliadas como supostamente indignas de viver é um efeito do racismo de sociedade e do Estado, sendo os corpos hierarquizados em escalas de valor, segundo critérios morais, normalizantes e da política criminal do direito penal do inimigo (Lemos et al., 2017: 168).

Sob essa lógica, a juventude das periferias é compreendida como ameaça e, em nome da garantia da ordem e da segurança pública, acabam por ser autorizadas e/ou naturalizadas práticas de violência, repressão e correção objetivando o controle dos jovens “perigosos” e “delinquentes”.

\section{A violência autorizada: o jovem negro e pobre como suspeito por excelência}

Ao longo do século XX, diversas práticas sociais e discursivas foram construindo uma imagem da juventude das classes populares no Brasil, vista, em larga medida, como fonte de ameaça e perigo, correlacionando juventude, pobreza e criminalidade. Essa imagem ganha contornos a partir de elementos díspares tramados no seio de discursos legitimados socialmente, tecendo a imagem de uma juventude perigosa sob a qual se justifica uma série de estratégias de controle e correção. Esses discursos perduram e se conectam na atualidade, produzindo verdades amplamente disseminadas, pelas quais a imagem do jovem negro e pobre se consolida como a figura do suspeito por excelência.

Sobre essa ideia de suspeição e desconfiança vinculada a uma parcela social, tomamos como referência para a discussão o conceito de sujeição criminal (Misse, 2014). Tal ideia implica uma construção social na qual "se dissemina uma expectativa negativa sobre indivíduos e grupos, fazendo-os crer que essa expectativa não só é verdadeira como constitui parte integrante de sua subjetividade” (Misse, 2014: 205). De acordo com o autor, a sujeição criminal parte da crença, compartilhada socialmente, de que o crime habita o sujeito, é parte constitutiva do seu 'ser'.

Misse afirma, ainda, que essa relação começa a se estabelecer mais fortemente no Brasil a partir da década de 1930, com os processos de industrialização e urbanização, por meio dos quais se inicia uma normalização repressiva das massas 


\section{A Violência enquanto Fenômeno Social..}

urbanas, organizando e categorizando indivíduos a partir da lógica dos tipos sociais, “por exemplo, ‘o malandro’, o ‘marginal’, o ‘vagabundo’” (Misse, 2014: 207). Cada um deles é valorado negativamente em relação à figura do cidadão, daquilo que é "chamado hoje de 'pessoas de bem’” (Misse, 2014: 207). A partir dessa prática discursiva e normalizadora em curso, a concepção da sujeição criminal se fortalece, sendo direcionada a indivíduos ou grupos sociais sobre os quais incide a expectativa do cometimento do crime.

\footnotetext{
Trata-se de alguém ou de um grupo social em relação ao qual "sabe-se" preventivamente que poderão nos fazer mal, assaltar-nos, violar-nos, matar-nos. São cruéis, matam por nada, não respeitam ninguém, não têm valores nem ideais, são "monstros", "animais", "pessoas do mal", bandidos infames. No limite, sua vida é indesejável para a sociedade” (Misse, 2014: 208).
}

Nesta direção, a sociedade passa a prevenir-se, partindo, principalmente, de estratégias e procedimentos de vigilância, controle e correção. Esses são exercidos a partir de "poderes laterais, à margem da justiça, como a polícia e toda uma rede de instituições de vigilância e de correção - a polícia para a vigilância, as instituições psicológicas, psiquiátricas, criminológicas, médicas, pedagógicas para a correção” (Foucault, 2003: 86). Tais práticas são exercidas em instituições que surgem para lidar com a ideia da periculosidade, sendo que, desde a lógica das virtualidades, "a vigilância sobre os indivíduos se exerce ao nível não do que se faz, mas do que se é; não do que se faz, mas do que se pode fazer” (Foucault, 2003: 104).

Ainda em relação ao conceito de sujeição criminal, para nossa discussão acerca dos elementos que constituem a juventude das periferias, cabe descrever algumas de suas principais dimensões. Em primeiro lugar, trata-se da expectativa compartilhada socialmente de que indivíduos e grupos, a partir de certas características, são mais propensos à criminalidade, atribuindo ao sujeito uma essência perigosa e irrecuperável (Misse, 2014). Isso evidencia uma perspectiva individualizante, naturalizante e culpabilizante. No contexto brasileiro, marcado pelas relações racistas legitimadas por discursos biologicistas e eugenistas, podemos afirmar que, em larga medida, é a figura do negro que surge historicamente como suspeita por excelência, sendo correlacionadas, “com frequência, características fenotípicas do negro ao comportamento criminoso, 
atribuindo-lhe uma natureza delinquente a priori, ou seja, estabelecendo o que seria a figura do ‘criminoso nato'” (Andrade, 2014: 259). Tal elemento nos auxilia a compreender a juventude negra como a maior vítima de homicídios no Brasil.

Outra dimensão que interessa destacar é a discriminação de características físicas e culturais que se associam a esses indivíduos ou grupos considerados perigosos. Características como "cor, roupas, marcas corporais, local de residência, modo de andar, origem social, etc.” (Misse, 2014: 209) tornam alguns sujeitos alvos de suspeição e criminalização, “apresentada e justificada como um critério preventivo de controle social” (Misse, 2014: 209).

No contexto laboral da Política de Assistência Social, é comum ouvir relatos de adolescentes moradores de regiões consideradas periféricas que passam, cotidianamente, por revistas policiais por andar com determinados tipos de roupa e acessórios que, nesse momento histórico, são associados ao mundo do crime. Boné de aba reta, cordão no pescoço, camisetas e shorts largos e coloridos, tênis chamativos são exemplos dessa caracterização. Esses têm seu acesso a espaços públicos e privados dificultados pela sua vestimenta, pela sua cor de pele (geralmente jovens negros). É comum ouvir também relatos de jovens e adultos que não são sequer chamados para entrevistas de emprego quando deixam seus currículos nas empresas por morarem em bairros da periferia considerados "perigosos", entre tantas outras situações que poderiam ser utilizadas para ilustrar essa dimensão.

A partir dessa associação, a figura do suspeito por excelência, na sociedade brasileira, adquire contornos muito claros: o jovem negro pobre e morador da periferia. E é sobre esse suspeito que incidem as práticas violentas e, principalmente, a violência letal, haja vista que, dadas as condições da sujeição criminal, àqueles que são considerados perigosos “a regra seguida não é a da 'presunção de inocência', mas a da desconfiança e da 'presunção (preventiva) de culpabilidade”” (Misse, 2014: 209). Essa forma de pensar e abordar o jovem, muitas vezes, legitima atos como "fazer justiça com as próprias mãos” ou, então, práticas de extermínio sob a alegação da proteção do “cidadão de bem” e do patrimônio. Trata-se de práticas e discursos altamente violentos, atualizados pelo cidadão comum, e que são amenizados pela afirmativa tantas vezes 


\section{A Violência enquanto Fenômeno Social..}

ouvida nos diversos contextos de que "bandido bom é bandido morto".

\section{Considerações Finais}

A associação entre a juventude das classes populares e violência vem ocorrendo desde longa data no país, mantendo- se como condição de possibilidade para a emergência de enunciados que vinculam a morte dessa parcela da juventude à criminalidade e à anormalidade como algo natural. Os dados estatísticos analisados nos mostram os efeitos sociais dessa vinculação ao apontar que certa parcela da juventude brasileira tem vivenciado uma realidade de violência e extermínio, fato esse que é pouco discutido e problematizado para além dos espaços acadêmicos e de militância.

Ademais, de acordo com as estatísticas apresentadas, homens jovens negros e pobres têm sido os principais alvos dessa prática. Tal fato demonstra que essa violência não é aleatória, mas pautada por uma série de preconceitos e estigmatizações perpetuadas histórica e socialmente e que se produzem, inclusive, a partir dos enunciados midiáticos presentes nos mais diversos meios de comunicação: jornalismo, telenovelas, blogs e sites.

Em relação à questão da violência cometida contra esses jovens, pobres e moradores de regiões periféricas e marginais, cabe sinalizar, que o homicídio se configura como o extremo de uma série de violências cotidianas, experienciadas no preconceito, nas práticas de exclusão, na ausência de serviços públicos de qualidade, na presença cotidiana e ofensiva dos aparatos militares das polícias nos territórios que ficam à margem dos centros urbanos, bem como na invisibilidade constante de suas trajetórias, que são reduzidas ao suposto envolvimento com o crime, tratando de forma estereotipada e generalizada esse recorte da população jovem brasileira. Reconhecemos aqui as experiências cotidianas de mortes simbólicas e reais que marcam esses corpos de maneira definitiva. Quando há crime, os dispositivos legais estão instituídos para que providências sejam tomadas, ainda que possam ser questionadas em sua eficácia. Entretanto, em uma sociedade que se mostra cada vez mais ávida por castigo, a perseguição e o assassinato dessa população jovem, sem mediação legal, dá indícios de 
uma barbárie que, pode-se dizer, já se encontra em curso.

Nesse sentido, a vida desses jovens se aproxima de maneira significativa daquilo que Agamben denomina como “vida matável” (Agamben, 2002: 84). Vida que é banida, olhada como elemento perigoso e que necessita, de alguma forma, deixar de existir, seja no plano simbólico, seja no plano concreto do extermínio. Vida exterminada, morte banalizada, inclusive entre eles próprios, "uma morte sem importância para eles - afinal, quem está na vida loka, reconhece de antemão seu destino” (Souza, 2012). O efeito violento desse discurso e dessa prática, em síntese, é o de que, em relação a essas vidas que não merecem viver, não haveria o que lamentar.

\section{Referências}

ABRAMOVAY, Miriam. et al., Juventude, Violência e Vulnerabilidade Social na América Latina: Desafios para Políticas Públicas, Brasilia: Unesco, BID, 2002.192p. Disponível em: $<$ http://repositorio.minedu.gob.pe/bitstream/handle/123456789/1379/2002_Abramo vay Juventud\%2c\%20violencia\%20y\%20vulnerabilidad\%20social\%20en\%20Am \%C3\%A9rica\%20Latina\%20desaf\%C3\%ADos\%20para\%20pol\%C3\%ADticas\%20 p\%C3\%BAblicas.pdf?sequence=1\&isAllowed=y > Acesso em: 12 dez. 2017.

AGAMBEN, Giorgio. Homo sacer: o poder soberano e a vida nua I. Belo Horizonte: Editora UFMG, 2002.

ALMEIDA, Suely.S. Violência e direitos humanos no Brasil. Revista Praia Vermelha. Estudos de Política e Teoria Social. UFRJ/PPGESS, v. 1, n. 11, p. 40-66, $2004 . \quad$ Disponível em: $<$ https://revistas.ufrj.br/index.php/praiavermelha/issue/viewIssue/ 758/268>. Acesso em: 23 maio 2017.

ANDRADE, Francisco .J.; ANDRADE, Rayane. Raça, Crime e Justiça. In: LIMA, R.S; RATTON, J.L, AZEVEDO, R.G. (Org.). Crime, polícia e justiça no Brasil. São Paulo: Contexto, 2014. p. 256-264.

BERNARDO, Renata. A construção da ameaça: juventude, delinqüência e educação nos primeiros tempos da república no Brasil (1890-1940). In: V CONGRESSO BRASILEIRO DE HISTÓRIA DA EDUCAÇÃO, 2008, Aracaju. Anais eletrônicos... Aracaju: O Ensino e a Pesquisa em História da Educação, 2008. Disponível em: <http://www.sbhe.org.br/novo/congressos/cbhe5/pdf/386.pdf >. Acesso em: 23 maio 2017. 
CARVALHO, Paulo.R Violência e Submissão: a gênese da consciência. In: NETO, A.A.; MANSANO, S.R. (Org.). Paixões tristes: retratos contemporâneos. São Paulo: Via Lettera, 2012. p. 11-22.

CERQUEIRA, Daniel. et al. Atlas da violência 2016. Brasília: IPEA. 2016. Disponível em:

$<$ http://www.ipea.gov.br/portal/images/stories/PDFs/nota_tecnica/160322_nt

17_atlas_da_violencia_2016_finalizado.pdf $>$. Acesso em: 01 abr. 2016.

CERQUEIRA, Daniel. et al. Atlas da violência 2017. Brasília: IPEA. 2017. Disponível em: $<$ http://www.ipea.gov.br/portal/images/170609_atlas_da_violencia_2017.pdf $>$. Acesso em 12 dez. 2017.

FELTRAN, Gabriel .S. Fronteiras de tensão: política e violência nas periferias de São Paulo. São Paulo: Editora Unesp, 2011.

FOUCAULT, Michel. Microfísica do poder: Organização e tradução Roberto Machado. Rio de Janeiro: Edições Graal, v. 4, 1979.

FOUCAULT, Michel. A verdade e as formas jurídicas. Tradução Roberto Cabral de Melo Machado e Eduardo Jardins Morais. Supervisão final do texto Lea Porto de Abreu Novaes et al. Rio de Janeiro: Editora NAU, 2003.

GUATTARI, Felix.; ROLNIK, Suely. Micropolítica: Cartografias do Desejo. Petrópolis: Editora Vozes, v. 6, 2000.

ÍNDICE DE HOMICÍDIOS NA ADOLESCÊNCIA (IHA). Organizadores Doriam Luis Borges de Melo, Ignácio Cano. Rio de Janeiro: Observatório de Favelas, 2014.

LEMOS, Flavia.C.S. et al. O extermínio de jovens negros pobres no Brasil: práticas biopolíticas em questão. Pesquisas e Práticas Psicossociais, v. 12, n. 1, p. 164176, 2017.2 Disponível em: <http://pepsic.bvsalud.org/scielo.php?script=sci_arttext\&pid=S1809890820170001 00012>. Acesso em: 05 nov. 2017.

LOPES, Roseli. E. et al. 3bJKE7PS. Saúde e sociedade, v. 17, n. 3, p. 63-76, 2008. Disponível em: <http://www.scielo.br/pdf/sausoc/v17n3/08.pdf>. Acesso em: 15 out. 2017

MELLO, Silvia .L. A violência urbana e a exclusão dos jovens. In: SAWAIA, B. (Org.). As artimanhas da exclusão: análise psicossocial e ética da desigualdade social. $4^{\mathrm{a}}$ ed. Petrópolis: Vozes, 2002.

MISSE, Michel. Sujeição Criminal. In: LIMA, R.S; RATTON, J.L; AZEVEDO, R.G. 
(Org.). Crime, polícia e justiça no Brasil. São Paulo, Contexto, 2014. v. 45, p. 154-155.

OLIVEN, Ruben. G. A violência como mecanismo de dominação e como estratégia de sobrevivência. In: Violência e cultura no Brasil [online]. Rio de Janeiro: Centro Edelstein de Pesquisa Social, $2010 . \quad$ Disponível em: $<$ http://books.scielo.org/id/b8n7j/pdf/oliven-9788579820069-02.pdf > . Acesso em: 12 dez. 2017.

RIZZINI, Irene.;LIMONGI, Natalia .S. Percepções sobre violência no cotidiano dos jovens. Revista Katálysis, Florianópolis, v. 19, n. 1, p. 33-42, jun. 2016.Disponível em <http://www.scielo.br/scielo.php?script=sci_arttext\&pid=S1414$\underline{49802016000100}$ 033\&lng=en\&nrm=iso> . Acesso em 12 out. 2017.

SILVA, Luiz.A.M. "Violência Urbana”, Segurança Pública e Favelas - O Caso do Rio De Janeiro Atual. Caderno CRH, Salvador, v. 23, n. 59, p. 283-300, maio./ago.2010.Disponível em: <http://www.scielo.br/pdf/ccrh/v23n59/06.pdf>. Acesso em 06 set. 2017.

SILVA, Luiz.A.M. Violência e ordem social. In: LIMA, R.S; RATTON, J.L, AZEVEDO, R.G. (Org.). Crime, polícia e justiça no Brasil. São Paulo: Contexto, 2014.

SOUZA, M.F.G. Dos campos de concentração às favelas brasileiras: a estratégia política soberana de gestão dos corpos na contemporaneidade. In: V Congresso Internacional de Psicopatologia Fundamental E XI Congresso Brasileiro De Psicopatologia Fundamental, 2012, Fortaleza. Anais...Fortaleza,2012. Disponível em:

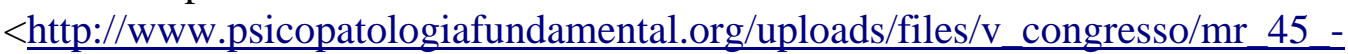
_marcelo_fonseca_gomes_de_souza.pdf $>$. Acesso em: 23 maio. 2017.

TAKEITI, Beatriz. A. Juventude(s), modos de subjetivação e violência: um diálogo com aportes de Michel Foucault. In: SPINK, M.J.P.; FIGUEIREDO, P.; BRASILINO, J. (Org.). Psicologia social e pessoalidade [online]. Rio de Janeiro: Centro Edelstein de Pesquisas Sociais; ABRAPSO, 2011, p. 59-75. Disponível em: $<$ http://books.scielo.org/id/xg9wp/pdf/spink-9788579820571-06. pdf > . Acesso em: 06 maio 2017.

TARRES, Joan.P.; MARTÍNEZ, Marisela.; MANSANO, Sonia.R.V. Corpos dóceis: novos contornos. In: NALLI, M.; MANSANO, S.R.V. Michel Foucault: desdobramentos. Belo Horizonte: Autêntica Editora, 2016.

WAIZELFISZ, Julio.J. Os jovens do Brasil: mapa da violência 2014. Brasília: Ministério da Saúde, 2014. Disponível em: $<$ http://www.mapadaviolencia.org.br/pdf2014/Mapa2014_JovensBrasil_Preliminar. pdf>. Acesso em: 10 maio 2016. 
WAISELFISZ, Julio. J. Mapa da Violência: Mortes Matadas por Arma de Fogo. Brasília: Secretaria-Geral da Presidência da República, Secretaria Nacional de Juventude, Secretaria de Políticas de Promoção da Igualdade Racial, 2015. Disponível em: $<$ http://www.mapadaviolencia.org.br/pdf2015/mapaViolencia 2015.pdf>. Acesso em: 23 maio 2017.

WAISELFISZ, Julio.J. Mapa da violência 2016: homicídios por armas de fogo no Brasil [Internet]. Brasília: FLACSO, 2016. Disponível em: <http://www.mapada violencia.org.br/pdf2016/Mapa2016_armas_web.pdf>. Acesso em: 23 maio 2017.

Recebido 09 de setembro 2018

Aprovado 15 de dezembro 2018 